\title{
Task-based Language Teaching in Southwest China: Insider Perspectives from Secondary School Teachers
}

\author{
Xuejun Ye \\ Centre for Language in Education, The Education University of Hong Kong, Hong Kong SAR, China
}

\begin{abstract}
A voluminous body of research has examined the implementation of task-based language teaching (TBLT). However, research investigating the implementation of TBLT in Southwest China remains limited. This article reports on a study of teachers' knowledge of TBLT, difficulties in deploying TBLT and their perceived feasible solutions. Thirteen teachers from a private junior secondary school in Sichuan, China participated in the semi-structured interviews. The findings reveal that teachers' understanding of TBLT was limited and varied. The implementation gap was attributed to various contextual constraints such as exams, teachers' beliefs, and pressures and challenges from the school. Participants of this study disseminated both similar and differentiated views towards problems and solutions. The study concludes by highlighting the need for an overhaul of the assessment and a reinforcement of teacher support and development.
\end{abstract}

Index Terms-Southwest China, task-based language teaching, secondary school, implementation gap, problems and solutions

\section{INTRODUCTION}

When China initiated the opening up and reform policy in the late 1970s, English has been gaining accelerating public importance and governmental attention (Hu, 2005b). The traditional English Language Teaching (ELT) approach in China combines grammar-translation and audio-lingual methods, characterized by thorough and systematic study of vocabulary, grammar and structural patterns (Hu, 2002a). The approach, however, has been unable to develop a satisfactory level of learners' communicative competence (Hu, 2002a).

Since the early 1990s, the Ministry of Education (MOE) has enthusiastically promoted the imported methodology, Communicative Language Teaching (CLT) to drive the ELT reform in response to a mounting dissatisfaction with the poor quality of ELT (Adamson \& Morris, 1997; Hu, 2002a, 2002b). However, contextual factors such as education tradition (Hu, 2002a) and non-communicative exams (Qi, 2007) have impeded the wide implementation of CLT (Deng \& Carless, 2009). Therefore, in the past decade, the MOE developed a revised National English Curriculum Standard, in which TBLT (task-based language teaching), an approach under the umbrella of CLT, was advocated (Hu, 2005b, 2013). It called for students' active participation in pair and/ or group work. Teachers are supposed to support students with meaningful classroom tasks and facilitate task completion through modeling, experiencing, practicing, participating, collaborating and communicating (Nunan, 2004). The rationale is that students learn the target language more effectively when involved in meaningful communicative activities, rather than focus on studying or manipulating grammatical rules (Ellis, 2003).

Despite the aim of bringing about changes in the education system, an implementation gap arises in the process. The implementation gap of this pedagogic innovation has been accompanied by soaring scholarly interest in the past fifteen years. Previous research has studied a myriad of contextual factors involving educational tradition, instructors, learners, institution and classroom that have emerged during the promotion of TBLT in secondary schools (Deng \& Carless, 2010; Luo \& Yi, 2013; Yan, 2015).

As shown in the article later, the majority of the studies were concentrated in coastal or developed regions such as Guangdong, Fujian, Zhejiang and Beijing (Deng \& Carless, 2009, 2010; Hu, 2013; Qi, 2007; Sun \& Cheng, 2000; Xie, 2010; Zheng \& Borg, 2014), with few cases concerning the less developed inland regions. Thereby, the existing findings may be over-generalized and cannot represent the whole situation of China, or at least some less affluent areas such as Sichuan. In order to bridge some of the gaps of current body of research, this article seeks to investigate what difficulties junior secondary English teachers have experienced during the implementation of TBLT in Sichuan.

\section{LITERATURE REVIEW}

\section{A. Problems Regarding TBLT}

Confucian thinking has much influence on the expected roles of both teachers and students and people's understanding of language learning (Scollon, 1999). In China, the primary role of the teachers is to transmit profound knowledge, and the students receive the authoritative knowledge passively, without challenging or interrupting their 
teachers, whereas in TBLT, teachers should employ learner-centered methods to facilitate the learning process (Adams \& Newton, 2009; Butler, 2011; Song, 2009). The conventional view of learning languages as a process of knowledge memorization and accumulation rather than a process for practical purposes has been accounted for the failure of nurturing students' communicative competence (Hu, 2002a; Penner, 1995).

As for learners, their reluctance to speak English and their diverse purposes of learning English have hampered the practice of TBLT (Lee, 2005; Sun \& Cheng, 2000; Yan \& He, 2012). Some students learn English only for passing exams, albeit having an increasing awareness of the importance of communicative competence (Teng, 2013). Their lack of motivation for speaking English results from the unavailability of a supportive language environment, where English is rarely used outside of the classroom (Hu, 2002b; Liu, 2016; Rao, 2002).

Apart from student resistance, many teachers were reported as having a minimal understanding of 'task' and TBLT, in parallel with insufficient knowledge about teaching English under the proposed TBLT method (Adams \& Newton, 2009; Deng \& Carless, 2010; Hu, 2013; Zheng \& Borg, 2014). Moreover, teachers' inadequate proficiency, together with students' limited proficiency in English, makes it difficult to carry out communication activities ( Hu, 2005a; Li \& Baldauf, 2011; Littlewood, 2007; Yan, 2012; Yu, 2001). Chinese is used as the main medium of instruction, with the grammar-translation method being the dominant approach. The exam-oriented teachers put absolute emphasis on language knowledge and exercises (Hu, 2013; Yan \& He, 2012). Their obsession with exams largely grows out of the current teacher evaluation system, which is chiefly based on test results (Yan, 2012).

Some common practical constraints shared by almost all schools are big class size, mixed-ability students, and limited time given for ELT. The class size of 50-60 students makes it very hard to engage in pair-work and group-work (Xie, 2010). A related issue to mixed-ability groups is the difficulty of selecting appropriate tasks and managing the class (Adams \& Newton, 2009). Normally the teachers spend a large amount of time covering the prescribed curriculum/exam content, leaving insufficient time for time-consuming communicative activities (Xie, 2010; Yan \& He, 2012; Zheng \& Borg, 2014).

A shared, pivotal challenge to the implementation of TBLT is the backwash effect of examinations, as it is intricately interwoven among factors vis-à-vis teachers, learners and administrators. Large-scale high-stakes tests play a gatekeeping role in primary, secondary and tertiary education; thus, determining how the curriculum is conveyed and studied (Adams \& Newton, 2009; Li \& Baldauf, 2011; Qi, 2007; Yan, 2012). Moreover, limited valuable training opportunities are provided for the further development of teachers (Adams \& Newton, 2009; Yan, 2012). Teachers' frustration becomes aggravated when they lack support from the school and parents, who are all obsessed with exam results (Deng \& Carless, 2010; Xie, 2010; Yan \& He, 2012). Deficiency in funding and equipment was recognized as another important constraint, which is particularly serious in economically underdeveloped areas (Rao, 2002; Xie, 2010; Yan, 2012).

\section{B. Solutions to the Implementation Gap}

Many scholars believed it essential that the non-communicative exams be geared towards evaluating students' individual understanding of knowledge and encouraging student-focused and learning-oriented teaching approaches (Yan, 2012). In this way, incentives can be generated for stakeholders to change methods, beliefs and attitudes (Deng \& Carless, 2010; Li \& Baldauf, 2011).

Teachers' beliefs were found to outweigh the high-stakes tests in shaping classroom teaching and learning (Deng \& Carless, 2010). Hu (2013) expatiated on shared characteristics of successful practitioners of TBLT, who resembled with respect to ways of improving themselves through reading TBLT theories and education methodologies, selecting practical and appropriate tasks, and implementing tasks that met the learning objectives and interests of students.

Teacher development programs should equip teachers with understandings of TBLT (Zheng \& Borg, 2014), enhance their decision-making abilities (Yan, 2012), and improve their pedagogical work (Yan \& He, 2012). Teacher support can be created through improving teachers' working conditions to conduct autonomous professional activities (Yan \& $\mathrm{He}, 2012$ ) and providing a positive social atmosphere to implement new approaches, which should be done by local authorities and schools acting as an inter-mediator between the teaching reform and parents (Xie, 2010).

Bax (2003) suggested that teachers use the 'context approach', during which they should first conduct a needs analysis and then identify a suitable approach integrating and reconciling both communicative and non-communicative activities (Liao, 2004; Meng, 2010; Rao, 2002; Sun \& Cheng, 2000). Likewise, Butler (2011) suggested that Littlewood's (2004) framework not be considered as an indicator of the desirability of activities, for activities with higher communicativeness are not always beneficial for learning.

Although most of the articles have provided a comprehensive and detailed analysis of the problems of and the solutions to the implementation gap of TBLT, there are, limitations that deserve to be discussed. The limitations are threefold: (1) previous studies were conducted exclusively in economically developed regions in China and were not demographically representative enough (Deng \& Carless, 2009, 2010; Hu, 2013; Zheng \& Borg, 2014); (2) some of the reported findings focused on pioneering schools where curriculum reform mandates have been implemented (Xie, 2010; Yan, 2012; Yan \& He, 2012); (3) these studies underscored innovative practices of a few reputable teachers (Deng \& Carless, 2009). The deliberately selected samples could not epitomize the general features of most English teachers in China. A limited number of studies cited above have investigated junior secondary English teachers' views on the obstacles of implementing TBLT, particularly those who teach different levels in the same grade. 
Therefore, the present study sets out to examine what difficulties junior secondary English teachers in Chengdu, Sichuan Province in Southwest China are faced with in deploying TBLT. Both similar and different difficulties that confront the teachers will be closely explored and compared. It is hoped that this study could fill the current research gap and enrich the literature with its findings and shed light on some implications for stakeholders, including policy-makers, schools, and teachers.

\section{Methodology}

\section{A. Context}

This study was conducted in a private foreign languages school in the capital city Chengdu, Sichuan in Southwest China. Consisting of kindergarten, primary school, junior secondary school and senior secondary school, the school has absolute right in admitting and grouping students based on either the internal entrance examination or the public examination. Junior secondary students are provided with three evening classes from Sunday to Friday, and three to five classes, according to their grade, on Saturday morning. Although the extra classes are not compulsory, almost all students and parents tacitly approve the arrangement. As one of the twenty-two demonstration secondary schools in Chengdu, English classes of the school are comprised of seven normal English classes using 'Go for it' and two oral English classes taught by a different teacher using 'Good English' each week. The school was selected as a research site because the author was once employed as an oral English teacher in the school.

\section{B. Participants}

There are in total fourteen teachers (who teach 'Go for it') in Grade Eight. Among them, thirteen teachers participated in this qualitative study. The teacher who teaches Class 2 was left out, for the students specialize in football and are not demanded to take senior secondary school entrance examination. Three factors were taken into account when selecting the participants. First, they taught in the same grade and had built a close rapport with the author, so reliable and abundant information could be elicited. Second, these teachers ranged from novice teachers to senior ones, and therefore, views of all age groups could be generated. Third, they taught different levels and were considered as ideal participants to breed diverse answers to the research questions. Table 1 provides the background information of the teachers with pseudonyms. If the same name occurs twice, it means the teacher teaches two classes. And their class information is shown in Table 2 respectively.

TABLE 1

TEACHERS' BACKGROUND

\begin{tabular}{|c|c|c|c|c|c|}
\hline & & & TEACHERS' & UND & \\
\hline \multirow[t]{2}{*}{ Class } & \multirow{2}{*}{$\begin{array}{l}\text { Name F: female } \\
\text { M: male }\end{array}$} & \multirow[t]{2}{*}{ Age } & \multirow[t]{2}{*}{ Qualifications } & \multicolumn{2}{|c|}{ Experience (years) } \\
\hline & & & & Teaching & Others \\
\hline 1 & Mina $(F)$ & 31 & $\begin{array}{l}\text { BA in English } \\
\text { Education }\end{array}$ & 11 & \\
\hline 3 & $\operatorname{Mina}(\mathrm{F})$ & & & & \\
\hline 4 & Amber (F) & 31 & $\begin{array}{l}\text { BA in English } \\
\text { Translation }\end{array}$ & 10 & \\
\hline 5 & Shinny $(F)$ & 32 & $\begin{array}{l}\text { BA in English } \\
\text { Education }\end{array}$ & 11 & $\begin{array}{l}\text { Taught Chinese in the US for one } \\
\text { year }\end{array}$ \\
\hline 6 & Dolly (F) & 28 & $\begin{array}{l}\text { BA in English } \\
\text { Education }\end{array}$ & 7 & $\begin{array}{l}\text { Taught high school English in an } \\
\text { education company for five years }\end{array}$ \\
\hline 7 & Andy (M) & 34 & $\begin{array}{l}\text { BA in English } \\
\text { Education }\end{array}$ & 11 & \\
\hline 8 & Tracy $(\mathrm{F})$ & 46 & $\begin{array}{l}\text { BA in English } \\
\text { Education }\end{array}$ & 24 & $\begin{array}{l}\text { Taught junior high school English } \\
\text { for ten years }\end{array}$ \\
\hline 9 & Amber (F) & & & & \\
\hline 10 & Janet $(F)$ & 31 & $\begin{array}{l}\text { BA in English } \\
\text { Education }\end{array}$ & 10 & $\begin{array}{l}\text { Taught primary school English in } \\
\text { an education company for six years }\end{array}$ \\
\hline 11 & Gloria $(F)$ & 38 & $\begin{array}{l}\text { BA in English } \\
\text { Education }\end{array}$ & 16 & \\
\hline 12 & Kitty (F) & 34 & $\begin{array}{l}\text { BA in English } \\
\text { Education }\end{array}$ & 11 & \\
\hline 13 & Dolly (F) & & & & \\
\hline 14 & Alicia $(F)$ & 24 & $\begin{array}{l}\text { BA in English } \\
\text { Education }\end{array}$ & 2 & \\
\hline 15 & Kitty $(\mathrm{F})$ & & & & \\
\hline 16 & Andy (M) & & & & \\
\hline 17 & Janet $(F)$ & & & & \\
\hline 18 & Alicia (F) & & & & \\
\hline 19 & Lucy $(\mathrm{F})$ & 29 & $\begin{array}{l}\text { BA in English } \\
\text { Education }\end{array}$ & 7 & $\begin{array}{l}\text { MA in Education Management (in } \\
\text { progress) }\end{array}$ \\
\hline 20 & Kelvin (M) & 34 & $\begin{array}{l}\text { BA in English } \\
\text { Education }\end{array}$ & 9 & Sold car insurance for four years \\
\hline 21 & Leslie (M) & 32 & $\begin{array}{l}\text { BA in English } \\
\text { Education }\end{array}$ & 9 & $\begin{array}{l}\text { Taught English (kids \& adults) in } \\
\text { an education company for two years }\end{array}$ \\
\hline 22 & Leslie (M) & & & & \\
\hline
\end{tabular}


TABLE 2

CLASS INFORMATION

\begin{tabular}{llllll}
\hline Class & $\begin{array}{l}\text { Numbers of } \\
\text { students }\end{array}$ & $\begin{array}{l}\text { Average score } \\
\text { (Mid-term) }\end{array}$ & Highest score & Lowest score & Standard deviation \\
\hline 1 & 38 & 96.671 & 131 & 47 & 22.6557 \\
3 & 42 & 77.762 & 129.5 & 21 & 31.6396 \\
4 & 47 & 127.032 & 140 & 79.5 & 10.3031 \\
5 & 41 & 132.171 & 144.5 & 105.5 & 7.7212 \\
6 & 48 & 105.906 & 131 & 41 & 19.9381 \\
7 & 52 & 107.375 & 137 & 60 & 17.777 \\
8 & 53 & 117.792 & 140.5 & 55.5 & 10.553 \\
9 & 50 & 126.67 & 142.5 & 77.5 & 24.5888 \\
10 & 41 & 93.78 & 130 & 36 & 2.969 \\
11 & 42 & 126.964 & 140.5 & 101.5 & 17.659 \\
12 & 39 & 86.962 & 122.5 & 21 & 29.4272 \\
13 & 55 & 108.545 & 133.5 & 40 & 20.7961 \\
14 & 43 & 98.047 & 133.5 & 39 & 29.0842 \\
15 & 48 & 102.25 & 133.5 & 40 & 20.8527 \\
16 & 45 & 88.167 & 136 & 35 & 21.0695 \\
17 & 42 & 103.726 & 137 & 48 & 19.8856 \\
18 & 52 & 111.981 & 139.5 & 33 & 23.761 \\
19 & 51 & 115.167 & 139.5 & 48 & 28.5741 \\
20 & 42 & 80 & 116.5 & 37.5 & 21.5315 \\
21 & 45 & 94.178 & 134 & 0.5 & \\
22 & 53 & 103.575 & 135 & 33 &. \\
\hline
\end{tabular}

The predominant research goal was to investigate what factors hampered teachers' implementation of TBLT. There are three research questions addressed in this study:

1. How much do teachers know about TBLT?

2. What difficulties teachers have experienced in deploying TBLT?

3. What are teachers' perceived possible solutions to the problems?

\section{Data Collection and Analysis}

Semi-structured interviews were employed in this qualitative research, allowing both the author and the thirteen teachers flexibility in producing themes that were pertinent to the research questions (Maykut \& Morehouse, 1994). An open-ended guiding protocol engaged by Chen and Wright (2016) was adapted in this interview (see Appendix 1). The interview centered on TBLT, including interviewees' knowledge of TBLT, trainings received about TBLT, perceived frequency of using TBLT, difficulties in employing TBLT, and possible solutions they proposed. Each interview lasted around 20-40 minutes, forming around 6.2 hours of data in total. The audio-recorded interviews were largely conducted in Sichuan dialect, enabling the subjects to express themselves fully. Nonetheless, they were allowed to speak Mandarin (Putonghua) or English whenever necessary or applicable.

Interview recordings were primarily transcribed into Chinese, verified by subjects with hardcopies later, and translated into English finally. Inductive analysis was adopted in data analysis (Miles \& Huberman, 1994). This study segmented transcripts of each interviewee according to the questions used in the interview guide (see Appendix 1) and employed codes, categories and themes to analyze each participant's transcripts. The codes, categories and themes were initially extracted from the contextual factors investigated by Deng and Carless (2010), Luo and Yi (2013) and Yan (2015). Nonetheless, newly emergent themes, categories and codes were also extracted and highlighted. Through repeated readings of the transcripts, recurrent codes, categories and themes were identified. Afterwards, all participants' data were synthesized, summarized and further grouped for comparison of teachers' shared or differentiated views on TBLT.

\section{FINDINGS}

\section{A. Teachers' Knowledge of TBLT}

One of the objectives of this study was to find out how much practitioners know about TBLT. They were asked about their knowledge of TBLT and whether they had received relevant trainings at the onset of the whole interview. Amber and Dolly acknowledged that they had not been trained to deploy this approach. Lucy and Alicia replied that they were introduced to TBLT during undergraduate study, but they forgot most of the theories. As to participants who admitted receiving trainings about TBLT, their answers still varied tremendously.

Gloria was recognized as the best English teacher in the school and won the first prize in the National Demonstration Class Competition in 2017. She delivered her understanding like this,

TBLT is to stimulate teaching through tasks. Before practicing, students are usually given a task to arouse their interest. For example, if students from another school are coming to know about the history and culture of ours. I tell my students that the best two students will be selected after class to interact with them. I provide them with a wide context and set a clear goal, and this guarantees a better result. 
Shinny, leader of Grade 8 English group, won the first prize in the Teaching Competition in the District level half a year ago, expressed her views on TBLT as follows:

It is dividing a class into a few steps. And there will be a task in each step. Teachers should motivate their students to use different tasks to achieve the final goal.

Tracy was regarded as the most senior teacher in the midst of all participants as she had been teaching for more than twenty years. As she said,

It is to ask students to finish tasks by themselves. They know clearly what they should do. I will guide them in the process. I think it is also called autonomous learning, which can enlighten the students.

Kitty responded directly,

I know nothing about TBLT. I never listened to the trainings even if I went there. But I try to provide as many activities for students.

Janet, Mina and Leslie claimed that there were just some demonstration classes inside the school. Janet and Mina admitted that they did not have a clear concept of TBLT. Leslie expressed his understanding in this way,

Teachers must know the objectives. Then he needs to determine the lesson type and correspondent teaching procedures to enable students to achieve their best ability. Actually, I do not know what TBLT is.

Kelvin stated and asked,

TBLT was mentioned frequently when I first came here. It is about cultivating students' speaking ability. But it seemed that it is seldom mentioned nowadays. Is it outdated?

Andy explained his understanding as follows:

There are many tasks in the teaching design. And there should be an authentic context in each task to encourage communication.

During the interviews, as demonstrated above, participants disseminated diversified understandings of TBLT, and some interviewees displayed little knowledge of TBLT. Therefore, before moving to the next research question, all participants were provided with a hardcopy of Nunan's (2004) definition of pedagogical tasks and Ellis (2009) discussion of four additional criteria that characterize a pedagogical task. After reading, all interviewees were demanded to recall their frequency of employing TBLT. Not surprisingly, teachers varied enormously in their responses. Some articulated that they used less than $10 \%$, while some held that the approach took up at least $90 \%$ of a whole class.

\section{B. Teachers' Perceived Difficulties in Employing TBLT}

This study sought to ascertain, from insiders' perspectives, what factors affected the effectiveness of the implementation of TBLT.

\section{Learner Factors}

The specific factors in terms of students mentioned by the interviewees are displayed in Table 3. An overwhelming number of teachers claimed that students' inadequate level of English impeded the use of TBLT. Some common explanations given by the teachers were students' lack of vocabulary, which restricted learners from expressing themselves. In worse situations, as Janet said,

Students' poor English forced me to speak Chinese sometimes. I have no way out because if I do not explain in Chinese, they will not understand even a word.

TABLE 3

LEARNER FACTORS MENTIONED BY PARTICIPANTS

\begin{tabular}{ll} 
& LEARNER FACTORS MENTIONED BY PARTICIPANTS \\
\hline Learner factors & Mentioned by participants \\
\hline English proficiency & Amber, Tracy, Lucy, Kitty, Janet, Mina, Kelvin, Dolly, Alicia, Andy \\
Beliefs about learning English & Leslie, Dolly \\
Motivation & Mina, Andy \\
Study habits & Janet, Andy \\
\hline
\end{tabular}

The second factor was students' wrong beliefs about learning English. As noted by the participants, students still regarded learning English equivalent to mastering grammar points, but not learning for communicative purposes. Some learners still preferred their teachers to use spoon-feeding methods. Dolly described this difficult situation as follows:

When I organized some pair or group activities, some students from Class 13 would be highly demotivated and would ask me to teach grammar points for exams.

The poorly motivated students aggravated teachers' deployment of TBLT. Andy articulated his opinions as follows:

How to make my students confident and motivated? I think they will only achieve this goal by making progress in study. But how can I help them make progress? This only proves to be a vicious cycle because my students, especially Class 16, are reluctant to learn.

Andy further expatiated on how students' bad study habits affect their English study. As he explained,

Many students' suffering should be largely attributed to their bad study habits formed earlier. Some parents never take their children's habits seriously. These children can never control themselves or focus on the teachers in class.

\section{Instructor Factors}


Table 4 lists four factors that shaped teachers' implementation of TBLT. The overarching factor stated by the participants was their incompetent proficiency in English, understanding TBLT and designing appropriate tasks. The lack of confidence was extremely conspicuous in new teachers. Both Dolly and Alicia noted,

As a new teacher, I really do not know how to teach important points and improve students' speaking at the same time.

TABLE 4

INSTRUCTOR FACTORS MENTIONED BY PARTICIPANTS

\begin{tabular}{llll}
\hline Instructor factors & Mentioned by participants & \\
\hline Comprehensive ability & Shinny, Tracy, Lucy, Mina, Kelvin, Dolly, Alicia & \\
Beliefs about English teaching & Gloria, Shinny, Amber, Kitty Lucy, Janet, Mina, Tracy & Leslie, Kelvin, Dolly, Andy, Alicia \\
Professionalism & Tracy, Lucy, Kelvin, Andy, Gloria & \\
Motivation & Tracy Andy & \multicolumn{1}{c}{ A } \\
\hline
\end{tabular}

Teachers demonstrated a huge difference with respect to their beliefs about English teaching. The first group of people (Gloria, Shinny, Amber, Kitty) attached more importance to the cultivation of students' communicative competence. As Gloria and Shinny commented,

As language teachers, we should help students achieve their long-term development, educate them as a human but not to produce machines who can only do exercises. Practice speaking does not necessarily threaten the test results. Actually, if a student does well in speaking, he will also excel in exams. Their exam results may decline when spending more time speaking, but this does not affect me.

The second group of people (Lucky, Janet, Mina, Tracy) realized the importance of fostering students' speaking capability and they tried to stick to their beliefs about teaching English in a more communicative way. However, they exhibited a certain level of deviation according to their description of their actual practice:

I have been reminding myself not to be too utilitarian. I should pay more attention to the improvement of students' communication skills. If I do not give students time to speak English, it will only be time shortage before exams. (Lucy)

The third group of teachers (Leslie, Kelvin, Dolly, Andy, Alicia) exemplified a high degree of unfaithfulness regarding the cultivation of students' communication competence. Some extracts are as follows:

I want to nurture students' speaking, but it is really hard. And in my view, we should develop more of students' reading and writing skills in Grade 8 . (Leslie)

I had thought about it in Grade 7. However, as the final exam approaches, I do not have the energy to do so. (Kelvin)

I personally think I will teach under the exam guidance. (Andy)

A few teachers displayed a relatively low level of professionalism by admitting that laziness and negative emotion, in fact, have impaired their implementation of TBLT. Their responses are as follows:

I am old so I do not want to learn. (Tracy)

I do not want to learn TBLT deeply. I have nothing to pursue. (Kelvin)

Sometimes I do not spend too much time preparing teaching materials, especially now when I am pregnant. (Lucy)

To be honest, sometimes I do not prepare lessons sufficiently. And for convenience reasons, I use the old courseware. (Andy)

People are emotional animals. Therefore, we may have bad mood. This influences my teaching. (Gloria)

Both demotivation and motivation were also closely observed and identified as barriers in the implementation of TBLT. Tracy complained that what she had done was not recognized and acknowledged by students, parents, colleagues and leaders. Henceforth, she was demotivated to devote more efforts. Andy, however, clarified that his motivation grew more from teaching students to get higher grades. He justified that this granted him a sense of achievement when receiving favorable remarks from others and also secured him a place in the school.

\section{Classroom-Based Factors}

Table 5 summarizes factors related to classroom. Most participants ascribed the difficulty of adopting TBLT to large class size, which generally brought about classroom management and monitoring problems. When coupled with mixed-ability class, it added paramount difficulties to teachers:

I am afraid that my noisy students would disturb neighboring classes. (Kitty)

High-achieving students can always find things to talk, while the low-achieving students usually chat with their neighbors. It is too demanding to monitor and observe each group at the same time. (Lucy)

The gap among the students is widening in Grade 8. It becomes super challenging to design tasks that cater to all students' needs. The male students outnumber the female ones in Class 22 . The naughty boys make the class noisy. (Leslie)

TABLE 5

CLASSROOM-BASED FACTORS MENTIONED BY PARTICIPANTS

\begin{tabular}{ll}
\hline Classroom-based factors & Mentioned by participants \\
\hline Class size & Gloria, Shinny, Lucy, Kitty, Mina, Leslie, Dolly, Alicia \\
Mixed-ability class & Gloria, Lucy, Janet, Mina, Leslie, Andy \\
Atmosphere & Gloria \\
\hline
\end{tabular}

Nevertheless, Gloria was the only participant who emphasized the importance of class atmosphere. As she said, 
You know I once had a demonstration class in Class 5. The students tended to be silent and did not talk much when I gave them tasks. These situations can be quite discouraging for teachers. However, there are always a few active students in Class 11, who can motivate the rest students.

\section{Textbook Factors}

Table 6 outlines two factors concerning textbooks. Gloria commented on the types of lessons,

When it is a grammar section in the unit, I have to sum up important grammar points and sometimes inevitably, give students non-communicative exercises.

TABLE 6

TEXTBOOK FACTORS MENTIONED BY PARTICIPANTS

\begin{tabular}{ll}
\hline Textbook factors & Mentioned by participants \\
\hline Types of lesson & Gloria \\
Topics and contents & Lucy \\
\hline
\end{tabular}

Lucy, however, highlighted the significance of topics involved in the textbook. She interpreted the topics as determinants of both instructors' and learners' motivation. As she explained,

If the topics are fascinating, I would like to spend more time preparing for the class. Students will be demotivated if the topics are not related to their life. Some texts are out-of-date. For example, there is a passage, which still talks about basic functions of robots, but actually robots can do much more than that. There is a huge discrepancy between students' background knowledge and the textbook.

\section{Societal-Institutional Factors}

As Table 7 presents, the senior secondary school entrance examination was accounted as the overriding reason for the implementation gap. Some practitioners complained,

Though there are only ten multi choices testing students' grammatical knowledge, some gap-filling questions, listening and writing are all concerned with grammars, like tense. I have to ask students to recite the words and phrases. (Tracy and Alicia)

Honestly speaking, in the second term of Grade 9, we only give students exercises to practice. Doing exercises and dictations really improve exam results. (Janet)

TABLE 7

SOCIETAL-INSTITUTIONAL FACTORS MENTIONED BY PARTICIPANTS

\begin{tabular}{ll}
\hline Societal-institutional factors & Mentioned by participants \\
\hline High-stakes exams & Gloria, Shinny, Amber, Tracy, Mina, Leslie, Dolly, Alicia \\
Teaching hours & Shinny, Lucy, Kitty, Janet, Mina, Leslie, Dolly, Alicia \\
Parents' support & Gloria, Shinny, Kitty, Mina, Leslie, Kelvin, Dolly, Andy \\
$\begin{array}{l}\text { Teacher evaluation system } \\
\text { Teacher trainings and }\end{array}$ & Janet, Leslie, Kelvin, Dolly, Alicia \\
demonstration classes & Shinny, Tracy, Dolly, Andy, kelvin \\
Other workloads & \\
Language environment support & Tracy, Janet, Mina, Andy \\
\hline
\end{tabular}

Time shortage was also classified as a fundamental factor that constrained teachers' practice of TBLT. Most practitioners reflected that only seven classes a week would not suffice for using TBLT, as there was an increasing amount of language points they needed to cover in Grade 8. As Dolly criticized,

As a foreign languages school, the school only allocates seven classes each week, which is fewer than math classes. But group discussions and pair work really take time. Especially when the final exam approaches, I really cannot give students chances to talk when I have not finished the book.

It is surprising that most teachers talked about the support they gained from the parents. Gloria was delighted to share her experience as follows:

Parents from Class 11 support my decision of spending more time promoting their kids' communication skills. Generally speaking, the high-achieving students' parents are more educated compared with those low-achieving ones'. They know what education is and will help drive their kids to practice oral English and give me feedback.

Conversely, not all teachers were as lucky as Gloria. The rest stated that they faced enormous pressure from the exam-obsessed parents. Kitty's response is just a case in point:

After all, these parents have paid so much tuition. Although knowing that their kids are underachieving, they still hope that the kids can be admitted to a good senior secondary school.

The strict evaluation of the teachers based on students' exam results extinguished their passion for deploying a communicative approach. A decline in ranking often led to income reduction and public criticisms. Leslie elaborated as follows:

Your income and self-esteem are not only decided by your ranking in the Grade. Even if you have satisfied this goal, your annul bonus decreases if the English team is not ranked the top three in the district. Even though the first two goals are attainable, the result will still be compared with other subjects of the same class.

Trainings and demonstration classes from various levels were reported as being ineffective, because they were not applicable. Some practitioners described, 
Last year the school designated me to observe demonstration classes in Hangzhou. Though I learned a lot, I still could not apply it to my class. (Tracy)

I think I need someone to direct and teach me to use TBLT. (Kelvin)

All teaching and research activities always focus too much on how to analyze the textbook and how to understand writer's purpose. Admittedly learning these is beneficial for high-achieving students. However, there is a constant lack of research on how to effectively teach the low-achieving students. (Andy)

Substantial workloads posed another great hindrance in constructing a supportive environment for TBLT. Some interviewees grumbled,

We spend a lot of time coping with leaders' checking of our attendance. As a head teacher, I am engaged in too many administrative tasks like attending meetings. (Tracy)

I teach two classes and my daily tasks are doing dictations to students, preparing teaching materials, assigning and checking homework, and talking with my students. Sometimes I really have no time to do lesson plan, so I can only give students an exam the second day instead. (Janet)

I counted that I need four hours to meticulously prepare for a 40-minute class. However, insisting on it made me both mentally and physically tired, because after finishing three classes in the morning, I have to hurry to check two classes' homework. In the afternoon, I usually prepare teaching materials for tomorrow. Sometimes I have to deal with students' homework, talk with parents or go to meetings. If unfortunately I have evening classes, I have to work overtime at home in the evening. (Mina)

The teachers judged the absence of English-speaking environment, which could be created by the school, as a challenge undermining teaching and learning. According to Kachru (1985) three concentric circles model, China falls into the Expanding circle because English, as a foreign language, is mainly used in restricted circumstances such as in the classroom. Tracy and Dolly delivered their opinions respectively,

The school has never thought of creating, for example, an English corner for the students to practice English. I hope you do not mind me saying that actually the oral English class is just lip service. The leaders do not really know nor care much about the class.

I received a training last month in a foreign languages school in Suzhou. It was amazing that the students even spoke English after class. Even the head teacher was required to learn English with and speak English to students. Their so-called English Class is allotted with twenty English classes each week, but how about ours?

\section{Teachers' Preferred Solutions to the Implementation Gap}

This study also aimed to find out participants' desired solutions to the current problems. Some teachers came up with only one solution, but some raised more than one resolution. Their responses could be summarized in three aspects.

From the broadest perspective, almost all interviewees stressed the necessity of overhauling the present high-stakes exam, which was the accepted prerequisite for engendering subsequent changes. Their suggestions included adding speaking as an essential component of the entrance exam, empowering all stakeholders to realize the importance of learning English for communicative purposes. Most of the respondents stressed the impossibility of institutional change at present. However, Gloria and Shinny stated that teachers and students should be well prepared for the revolution of the current assessment system, because an overhaul of Gaokao (College Entrance Examination) and Zhongkao (Senior Secondary School Entrance Examination) were proposed in the Nineteenth National Congress. They pointed out that the initial implementation in Beijing in 2020 would undoubtedly accelerate the reform nationwide. Trainings and demonstration classes should also be geared toward resembling and reflecting front-line workers' individual and practical needs to enable teachers and students to be real beneficiaries of this prevalent pedagogy. Although Lucy enunciated the high cost that the timely revision of the textbook might come with, she still considered it indispensable for textbook writers to conduct a more comprehensive and profound needs analysis of both students and teachers.

From the school level, teachers seemed to yearn for more changes. More than half of the teachers anticipated that the current evaluation system not to be too much exam-based. They advocated taking teachers' daily performance in the classroom into consideration. Teachers, generally, called for an increase of teaching hours, allowing them to implement the time-consuming approach and cover all language points simultaneously. Mina, however, longed for less extra working hours on weekday evenings and Saturday morning. In this way, she could invest more energy and time in lesson planning. Both Amber and Mina recommended the mobile learning system, which guaranteed that students were placed at the proper level of their competence and also stimulated students' mobility among classes. They appreciated this mode but they still argued that the student management problems could be an obstruction. Meanwhile, the school could also support learners by simulating an ESL environment to encourage more English use outside of the classroom.

Being disappointed with the policymakers and school administrators, some teachers maintained that at least they could help ameliorate the existing plight by themselves. Among them, Gloria and Shinny underlined teachers' obligations to improve themselves by primarily changing their attitudes from teaching for exams to teaching for communicative purposes. A holistic development of their skills could also be achieved by taking advantage of online resources to enhance English proficiency and lesson planning expertise. Dolly and Kitty proposed that teachers could act as a catalyst in reshaping both parents' and students' view on learning English. Janet' eclectic resolution appeared reasonable and feasible, i.e., to employ TBLT to develop students' communicative competence in class and to enhance students' academic performance through making use of extra-curricular time. 


\section{DISCUSSION}

This paper has created an abundant source of teachers' implementation of TBLT in a private foreign languages school in Southwest China. By conducting in-depth semi-structured interviews with thirteen teachers, respondents' knowledge of TBLT, perceived difficulties in deploying TBLT and possible solutions were generated to breed some tentative insights and summaries.

The first research question identified teachers' knowledge of TBLT. Generally, participants lacked an adequate understanding of this pedagogy and their interpretations of 'task' varied substantially. Their responses indicated that TBLT usually involved goals, outcomes and communication in forms of pair work and group discussions. Some even declared an almost total absent knowledge of TBLT. The deficient and too broad understandings of TBLT can be primarily attributed to the failure of the 2001 NECS (National English Curriculum Standard) in defining precisely what a 'task' is (Hu, 2013; Zheng \& Borg, 2014). Other reasons could be a noticeable decline of relevant trainings in recent years and teachers' insufficient intrinsic motivation to learn this pedagogy, both of which could account for the unsatisfactory findings.

The second research question examined teachers' insider perceptions of the specific obstacles that prevented the implementation of TBLT in their workplace, which was the predominant goal of this study. The findings echoed previous studies (Deng \& Carless, 2010; Hu, 2002a; Li \& Baldauf, 2011; Rao, 2002; Yan, 2015) in that constraints like high-stakes exams, student resistance, teachers' proficiency, large class size, mixed-ability class, the evaluation system of the teachers, were all identified within the context. In the same vein, backwash effect of exams was the overarching factor that posed influences on all stakeholders from all levels. In line with Li and Baldauf's (2011) study, the in-service trainings and demonstration classes were reflected as ineffective and impractical in teachers' individual context. A distinctive feature of this study was that teachers' laziness was discovered as a new instructor factor, which was seldom discussed by other studies. The obtainment could be ascribed to the author's affinity with the interviewees, allowing additional hidden factors to be revealed. Remarkably, the findings also suggested that there existed differentiated perceptions of the teachers. Participants who taught high proficiency students seemed to be least affected by exams and displayed positive views and confidence in cultivating students' communicative competence, while those taught mid or low-level classes were explored as being ambivalent towards practicing students' communication skills. Teachers of lower level classes, particularly novice teachers, were also examined as confronting more pressures from the school's evaluation system. Their situations were aggravated if they taught two classes or if they were head teachers, facing severe time shortage and enormous administrative workloads, characteristics of private schools.

The final research question investigated teachers' analyses of potential reconciliations between the implementation gap and status quo. Although exam was measured as the determinant in the reform process, it was not ranked as the primary consideration for an amendment, for more than half of the respondents reiterated that examination reform was completely beyond their control. The supports from the school, however, emerged as teachers' major preference for solutions. Having realized that teachers' evaluation system was immutable or might even exacerbate, as noted above, most exhausted teachers who were responsible for two classes and/ or taught low-achieving classes anticipated more teaching hours in the normal curriculum and less extra working hours in the evenings and weekends accordingly, which enabled these overburdened employees ample time to raise students' marks without sacrificing the implementation of TBLT. Other school-level suggestions such as diminishing class size and steering the mobile learning system were all observed as being somewhat not entirely applicable and practical. Teachers of high-achieving classes, on the contrary, sought to resolve problems by reflecting on themselves, as they insisted that that was how they could really make a difference.

\section{CONCLUSION}

This study has identified teachers' knowledge of TBLT, the problems encountered during the implementation of this pedagogy and their perceived feasible solutions to the difficulties. The findings have been illuminated by semi-structured interviews of thirteen teachers. The findings indicate that teachers' understanding of TBLT was limited and varied. The study confirms that contextual factors concerning students, instructors, classroom, school administration and policies continued to exert a profound influence on teachers' implementation of TBLT, which proved to resonate previous research. However, specific factors reported by teachers differed based on their individual roles and responsibilities. It also suggests that teachers displayed both resonances and dissonances when required to raise some viable solutions.

Two implications can be derived from this study. First, urgent action needs to be promoted, including reforming the Chinese education system on a national scale. It is imperative that the non-communicative assessment should be overhauled to meet the new curriculum goal of cultivating students' competence, which can stimulate changes undertaken by all stakeholders, including curriculum developers, textbook writers, school administrators, teachers, parents and students. Second, the support and development of teachers need to be reinforced. In-service trainings should be geared towards providing effective and practical solutions to address participants' specific context, which can be accomplished by firstly establishing a database of information about schools, teachers and students. This supports teacher educators in their efforts to pinpoint targeted trainings. Schools are also supposed to experience changes and 
reforms. They can alleviate teachers' stress through hiring more teachers to guarantee 'one class one teacher'. The mobile learning system can be successfully introduced if a teaching assistant can be assigned to each class to resolve student management problems, the extra cost of which can be subsidized by the local government. Teachers are also obliged to stick to the belief of fostering a holistic development of the students. Their determination can be maintained and fortified if such a belief can go through a 'brainwash' process in trainings and onsite meetings, empowering the recognition and internalization of the view.

The limitations of this study must be acknowledged. Although the primary goal of this research was not the actual performance of TBLT in the classroom, teachers' responses could be more objective if the study could be triangulated with classroom observations. In addition, the narrow scope of the qualitative study only concerned thirteen participants in the same school. Generalizations about junior secondary schools in Sichuan or in China, therefore, cannot be drawn from the study, given the economic, cultural and demographic diversity of China. Nevertheless, as teachers who taught both high, mid, and low achieving students were involved, this in-depth research has therefore, created a valuable point of reference for language planners, policy makers, school administrators and teachers in understanding a relatively comprehensive status in quo of the implementation gap of TBLT in Southwest China. Above all, secondary school practitioners can obtain a profound understanding of and reflect on their teaching practice of TBLT, from which they can, hopefully, find some possible solutions to their individual dilemmas within their capacity.

\section{APPENDIX}

Interview Guide

1. How much do you know about TBLT? Have you received any training about TBLT?

2. How often do you use TBLT? What do you think of this approach (effective or not)?

3. What difficulties have you experienced in employing TBLT? What obstacles would you attribute to?

\section{ACKNOWLEDGMENTS}

I would like to sincerely thank the participants for their cooperation, without whom this research was not possible.

\section{REFERENCES}

[1] Adams, R., \& Newton, J. (2009). TBLT in Asia: constraints and opportunities. Asian Journal of English Language Teaching $19.1,1-17$

[2] Adamson, B., \& Morris, P. (1997). The english curriculum in the people's republic of China. Comparative Education Review 41.1, 3-26.

[3] Bax, S. (2003). The end of CLT: a context approach to language teaching. ELT Journal 57.3, 278-287.

[4] Butler, Y. G. (2011). The implementation of communicative and task-based language teaching in the Asia-Pacific region. Annual Review of Applied Linguistics 31, 36-57.

[5] Chen. Q., \& Wright, C. (2016). Contextualization and authenticity in TBLT: voices from Chinese classrooms. Language Teaching Research 21.4, 517-538.

[6] Deng, C. R., \& Carless, D. R. (2009). The communicativeness of activities in a task-based innovation in Guangdong, China. Asian Journal of English Language Teaching 19, 113-134.

[7] Deng, C.R., \& Carless, D. R. (2010). Examination preparation or effective teaching: conflicting priorities in the implementation of a pedagogic innovation. Language Assessment Quarterly 7.4, 285-302.

[8] Ellis, R. (2003). Task-based Language Learning and Teaching. Oxford, U.K.: Oxford University Press.

[9] Ellis, R. (2009). Task-based language teaching: sorting out the misunderstandings. International Journal of Applied Linguistics $19.3,221-246$.

[10] Hu, G. W. (2002a). Potential cultural resistance to pedagogical imports: the case of communicative language teaching in China. Language, Culture and Curriculum 15.2, 93-105.

[11] $\mathrm{Hu}, \mathrm{G}$. W. (2002b). Recent important developments in secondary english-language teaching in the people's republic of China. Language, Culture and Curriculum 15.1, 30-49.

[12] Hu, G. W. (2005a). Contextual influences on instructional practices: a Chinese case for an ecological approach to ELT. TESOL Quarterly 39.4, 635-660.

[13] Hu, G. W. (2005b). English language education in China: policies, progress, and problems. Language Policy 4.1, 5-24.

[14] Hu, R. (2013). Task-based language teaching: responses from Chinese teachers of english. TESL-EJ 16.4, 1-21.

[15] Kachru, B. B. (1985). Standards, codification, and sociolinguistic realism: the english language in the outer circle. In R. Quirk and H. Widdowson (eds.), English in the World: Teaching and Learning the Language and Literatures. Cambridge: Cambridge University Press, 11-36.

[16] Lee, S. M. (2005). The pros and cons of task-based instruction in elementary english classes. English Teaching 60.2, 185-250.

[17] Li, M., \& Baldauf, R. (2011). Beyond the curriculum: a Chinese example of issues constraining effective english language teaching. TESOL Quarterly 45.4, 793-803.

[18] Liao, X. Q. (2004). The need for communicative language teaching in China. ELT Journal 58.3, 270-273.

[19] Littlewood, W. (2004). The task-based approach: some questions and suggestions. ELT Journal 58.4, 319-326.

[20] Littlewood, W. (2007). Communicative and task-based language teaching in East Asian classrooms. Language Teaching 40.3, 243-249. 
[21] Liu, W. (2016). The changing pedagogical discourses in China: the case of the foreign language curriculum change and its controversies. English Teaching: Practice \& Critique 15.1, 74-90.

[22] Luo, S. Q., \& Yi, B. S. (2013). TBLT in China (2001-2011): the current situation, predicament and future. Indonesian Journal of Applied Linguistics 2.2, 147-155.

[23] Maykut, P. S., \& Morehouse, R. E. (1994). Beginning Qualitative Research: A Philosophic and Practical Guide. London: Falmer Press.

[24] Meng, Y. (2010). College students' perceptions on the issues of task-based language teaching in Mainland China. Journal of Language Teaching \& Research 1.4, 434-442.

[25] Miles, M. B., \& Huberman, A. M. (1994). Qualitative Data Analysis. Thousand Oaks, CA: Sage.

[26] Nunan, D. (2004). Task-Based Language Teaching. Cambridge, U.K.: Cambridge University Press.

[27] Penner, J. (1995). Change and conflict: introduction of the communicative approach in China. TESL Canada Journal 12.2, $1-17$.

[28] Qi, L. X. (2007). Is testing an efficient agent for pedagogical change? Examining the intended washback of the writing task in a high-stakes english test in China. Assessment in Education: Principles, Policy \& Practice 14.1, 51-74.

[29] Rao, Z. (2002). Chinese students' perceptions of communicative and non-communicative activities in EFL classroom. System $30.1,85-105$.

[30] Scollon, S. (1999). Not to waste word or students: Confucian and Socratic discourse in the tertiary classroom. In E. Hinkel (ed.) Culture in Second Language Teaching and Learning. Cambridge: Cambridge University Press, 13-27.

[31] Song, Y. (2009). How can Chinese english teachers meet the challenge of creating a learner-centered, communicative, intercultural classroom to achieve optimal student learning outcomes? Canadian Social Science 5.6, 81-91.

[32] Sun, G. Y., \& Cheng, L. Y. (2000). From context to curriculum: a case study of communicative language teaching in China. TESL Canada Journal 19.2, 67-86.

[33] Teng, F. (2013). EFL learner's difficult role transition from secondary school to university: from the perspective and perceptions of EFL teachers of TBLT in western China. International Journal of English Language \& Translation Studies 1.2, $11-32$.

[34] Xie, C. M. (2010). An investigation into the 2003 new english curriculum in China through teachers. Sino-US English Teaching $7.8,30-36$.

[35] Yan, C. (2012). 'We can only change in a small way': a study of secondary english teachers' implementation of curriculum reform in China. Journal of Educational Change 13.4, 431-447.

[36] Yan, C., \& He, C. (2012). Bridging the implementation gap: an ethnographic study of english teachers' implementation of the curriculum reform in China. Ethnography and Education 7.1, 1-19.

[37] Yan, C. (2015). 'We can't change much unless the exams change': teachers' dilemmas in the curriculum reform in China. Improving Schools 18.1, 5-19.

[38] Yu, L. (2001). Communicative language teaching in China: progress and resistance. TESOL Quarterly 35.1, $194-197$.

[39] Zheng, X., \& Borg, S. (2014). Task-based learning and teaching in China: secondary school teachers' beliefs and practices. Language Teaching Research 18.2, 205-221.

Xuejun Ye is a research assistant at the Centre for Language in Education, The Education University of Hong Kong. She is currently co-working on the development of an exemplar-based writing instruction textbook for teaching IELTS writing. She graduated with a master's degree in English Language Studies from The Hong Kong Polytechnic University. She worked for English First as an English teacher for adults and was a teacher of oral English at a key foreign languages secondary school in Sichuan, China. She was assigned by FLTRP (Foreign Language Teaching and Research Press) of China to write teachers' book for Sunshine Classics Graded Readers. Her research interests include Second Language Learning, Second Language Teaching and Second Language Writing. 